\title{
UN EPISODIO RELEVANTE: LA BURBUJA ESPECULATIVA Y LA CRISIS INMOBILIARIA EN PERSPECTIVA
}

\author{
José Manuel Naredo (Dr. Economista - Profesor Ad Honorem DUyOT)
}

\section{CONTEXTO}

A mi juicio, el episodio más relevante y condicionante para el territorio y el urbanismo de finales del siglo pasado y principios del actual, ha sido la enorme burbuja especulativa y la posterior crisis inmobiliaria que ha vivido el país. El pinchazo de esta burbuja ha forzado la crisis económica y también la del modelo inmobiliario que la posibilitó, invitando a reflexionar sobre él.

El modelo económico-inmobiliario condiciona el modelo territorial y urbano: en la medida en la que impera el modelo económico que trata el suelo y la vivienda, no como bienes de uso, sino como activos patrimoniales en los que invertir para obtener plusvalías, se impone también un mismo modelo de orden territorial, urbano y constructivo. Pues, como he venido subrayando, la globalización de ese modelo económico genera por todas partes, sin decirlo, la polarización territorial, la dispersión urbana y la uniformidad constructiva, en ausencia de otras orientaciones y frenos.

\section{EL MODELO INMOBILIARIO ESPAÑOL, SU CULMINACIÓN Y CRISIS}

El actual modelo inmobiliario no ha resultado de aplicar ningún plan teórico premeditado, sino de la configuración histórica de un marco institucional en el que se solapan aspectos e instrumentos (políticos, económicos, jurídicos, ...) orientados por el poder de determinados intereses oligárquicos. Es este poder oligárquico el que se impone y da unidad al modelo en toda nuestra geografía, trascendiendo la casuística de las legislaciones autonómicas.

Durante el franquismo se instalaron dos características esenciales del modelo: $1^{\circ}$ ) Los empeños especulativos de algunos se impusieron sobre otros posibles criterios de ordenación urbana y territorial más acordes con los intereses generales de la ciudadanía. Se extendió la cultura del "pelotazo" y el virus de la especulación por todo el cuerpo social. $2^{\circ}$ ) La vivienda libre y en propiedad se acabó imponiendo sobre la vivienda en alquiler $y$ en alquiler social.

Tres condiciones permitieron la culminación del modelo: $1^{a}$ ) La refundación oligárquica del poder que resultó de la metamorfosis democrática del franquismo, engendró una especie de neocaciquismo en el que los más poderosos continuaron tomando las grandes decisiones de espaldas a la ciudadanía. $2^{a}$ ) La crisis de la planificación territorial y urbana, permitió instalar un laissez faire de los poderosos. Es decir que se instaló, no el laissez faire igualitario y democrático que predica el liberalismo, sino un laissez faire elitista que permitió a los nuevos caciques desarrollar sin trabas sus lucrativas "operaciones" inmobiliarias en el conjunto del territorio. La propia palabra "operaciones", tomada del lenguaje militar, denota la intervención directa del poder en la toma de decisiones, por caminos que ajenos a ese mercado libre, transparente e igualitario cuyas propiedades benéficas ensalzan los manuales 
de economía. 3a) La adhesión de España a la Unión Europea y la entrada en el euro facilitó la financiación barata y abundante que alimentó los procesos especulativos hasta niveles sin precedentes.

\section{CONSECUENCIAS}

La confluencia de esas tres condiciones hizo un cocktail explosivo para el urbanismo y el territorio: desencadenó una burbuja inmobiliario-especulativa sin precedentes, que provocó una sobredosis constructiva que hizo de España el país europeo con más viviendas, kilómetros de autopista, de AVE, puertos y aeropuertos por habitante. Pero el estancamiento demográfico y la ausencia de vivienda social, hizo también de España líder europea en viviendas vacías o infrautilizadas, manteniendo a la vez personas sin vivienda o hacinadas en infraviviendas.

Se acentuó también una extrema polarización territorial: España cuenta con grandes aglomeraciones de población, pero a la vez con grandes territorios vacíos, con menos de un habitante por kilómetro cuadrado. En Europa no se encuentran zonas de tan baja densidad poblacional, como no sea en las proximidades del Círculo Polar Ártico, o en el desierto lapón. España es también líder europeo en pueblos abandonados y en patrimonio inmobiliario rural en ruina.

Se impuso el urbanismo disperso: hay varias tesis doctorales en la Escuela de Arquitectura de Madrid, que muestran que las "operaciones" inmobiliarias han desarrollado en la metrópoli un urbanismo disperso, guiado por los grandes ejes del viario y por el poder de los propietarios de terrenos, ajeno a las previsiones del planeamiento.

Finalmente, el intenso proceso de destrucción de edificios antiguos, por demolición o ruina, y de construcción nueva repetitiva, orientada a obtener plusvalías de la reclasificación y recalificación de suelo, originó la monotonía y mala calidad del entorno urbano.

Podríamos poner como ejemplo de "operaciones" la que modificó la utilización de la antigua ciudad deportiva del Real Madrid, para meter allí un gran volumen de construcción en altura que cambió el skyline de la ciudad y arrojó enormes plusvalías. O, en las proximidades de Madrid, los casos de la "Ciudad Valdeluz" en Yebes, o de "Residencial el Quiñón" en Seseña, con unas diez mil viviendas proyectadas cada uno, pero con sólo unos cientos de habitantes residiendo, lo que indujo a llamarlas "ciudades fantasma". Debe de quedar claro que el objetivo de las "operaciones", no es hacer ciudad, sino maximizar las plusvalías de los propietarios de suelo añadiendo varios ceros a su valor por el mero hecho de ampliar su edificabilidad. Estos trozos de ciudad no siguen ninguna racionalidad de planeamiento, sino que ilustran esa especie de urbanismo a la carta de los especuladores más poderosos. Según mis cálculos, en los años centrales del boom inmobiliario, estas plusvalías han superado ampliamente los ingresos ordinarios de la población.

Esta avalancha de "operaciones" además de extender por toda la geografía española el modelo urbano disperso, invirtió en las zonas más densas el modelo originario de ocupación del territorio: transformó un mar de ruralidad con islotes urbanos en un mar metropolitano con islotes de naturaleza o ruralidad degradada que 
ahora se trata de proteger. El nuevo modelo consume mucho más suelo y recursos que el anterior: por ejemplo, la Comunidad de Madrid ha más que duplicado la ocupación del suelo por habitante, al disparase las servidumbres indirectas que el dicho modelo exige en forma de actividades extractivas y de vertido, embalses, viario, suelo en promoción, etc.

El nuevo modelo de urbanismo disperso no ha tendido a mejorar, sino a destruir los asentamientos anteriores. Ha destruido los asentamientos lejanos, al vaciarlos de población y actividades, sometiéndolos al abandono y la ruina. Y engullido los próximos al arrojar sobre ellos tal contenido de edificaciones e infraestructuras, dejando las muestras de lo que había como algo testimonial o sin sentido.

El nuevo modelo constructivo, industrializado, homogéneo, repetitivo, genera una especie de "estilo universal" que, lejos de mejorar, destruye los edificios de la ciudad clásica o histórica. Basta con que se pueda aumentar el volumen construido de las parcelas, para que se condene a la demolición los edificios antiguos y se imponga el nuevo "estilo universal" multiplicando la superficie construida. Más de la mitad de las viviendas registradas en el Censo de 1950 han desaparecido hoy por demolición o ruina.

Al ser la construcción nueva de edificios e infraestructuras, colaboradora necesaria del negocio inmobiliario, ésta se ha disparado hasta límites que parecían impensables. España vino construyendo, en los años centrales del pasado boom inmobiliario, más del doble de viviendas que Francia y Alemania juntas, cuando estos dos países triplican a España en población y la duplican en superficie. Tomando el consumo anual de cemento como indicador sintético de la actividad constructiva, nos encontramos con que se acercó en los años centrales del boom a los sesenta millones de toneladas, cayendo sobre el territorio más de una tonelada de cemento por hectárea y cerca de diez toneladas de cemento mezclado ya con grava, arena etc. Lo cual hace que la palabra tsunami inmobiliario deje de ser una simple metáfora para cargarse de materialidad.

Este proceso de ocupación efectiva del suelo por construcciones e infraestructuras (conocida como "sellado" de suelos) originó una destrucción territorial mucho más amplia, no solo por servidumbres de extracciones, vertidos, embalses,...sino también por suelo en promoción o en "barbecho urbano". Las desmesuradas expectativas de urbanización han generado muchos miles de hectáreas de sistemas agrarios abandonados y sometidos a deterioros diversos. La burbuja inmobiliaria nos ha legado así, un sobredimensionado y dantesco espacio periurbano degradado.

El pinchazo de la burbuja inmobiliaria ha acentuado la depresión de la economía española recordando con dramatismo que los movimientos especulativos son juegos de suma cero, en los que algunos ganan porque a la postre otros pierden o se endeudan para seguir sufragando las plusvalías que cobraron los ganadores. Muchos tendrán que seguir pagando, porque la financiación de la burbuja inmobiliaria y sus megaproyectos asociados, devoró el ahorro financiero del país, tornándolo negativo en los últimos años del boom, e induciendo a la banca a seguirlo financiando hasta el final con dinero de fuera. Finalmente, cuando las suspensiones de pagos de las inmobiliarias y empresas asociadas extendieron la desconfianza, desapareció la liquidez barata y abundante que el país venía recibiendo de fuera, colapsó el sistema 
financiero, acarreando la consabida "sequía de créditos", las operaciones de salvamento del Estado y las inyecciones de liquidez del BCE.

El andamio especulativo inmobiliario-financiero instalado durante el auge acabó situando el endeudamiento hipotecario de la economía española respecto a la renta por encima del de todos los países de nuestro entorno, incluido EEUU, cuando antes de la burbuja se situaba por debajo. El hecho de que el grueso de la deuda hipotecaria de los hogares recaiga sobre los escalones más bajos de renta, aumenta sus dificultades de pago convirtiendo la crisis económica en crisis social (por ejemplo, en 2011, el $20 \%$ de los hogares endeudados con menos renta tuvo que destinar al pago de la deuda más del 46 \% de sus ingresos, según la EFF del Banco de España).

Por otra parte, el monocultivo inmobiliario imperante trajo consigo tasas de paro muy superiores a las de los otros países de la UE (que no pudo corregir ninguna "reforma laboral", cuando el grueso del paro provino de actividades directa o indirectamente afectadas por el desplome de la construcción y la promoción inmobiliaria).

Cabe preguntarse qué ha cambiado para hacer tan gravosas unas deudas que durante el auge parecían soportables. El principal cambio viene de la diferente naturaleza de los activos y pasivos que componen el balance de hogares y empresas. Mientras que el valor de los inmuebles y terrenos cae, junto con los ingresos, el valor de las deudas permanece invariable o puede aumentar si lo hace el tipo de interés. En este contexto asistimos en España a un forcejeo para ocultar o maquillar la caída de los precios que se observa en el mercado inmobiliario. Al principio de la crisis, las empresas de tasación, mayoritariamente dependientes de bancos y cajas de ahorros, retrasaron más de un año la caída de precios de la vivienda registrada en los precios de los anuncios, cuya caída total superó a la de los precios de tasación (y recordemos que en momentos de crisis los precios de mercado caen bien por debajo de los de los anuncios, pero no salen en la foto de nuestras precarias estadísticas). Si al principio los precios de tasación trataron de ilustrar un "aterrizaje suave", ahora se apresuran a anticipar "el repunte", mientras que los de los precios anuncios siguen cayendo. Así, la opacidad estadística sobre la evolución de los verdaderos precios de mercado retrasa los ajustes en el mercado inmobiliario, manteniendo un patrimonio inmobiliario sobredimensionado y en buena parte desocupado, que enfrenta viviendas desocupadas a necesidades de vivienda insatisfechas, agravadas por ola de desahucios en curso, haciendo más penosa la crisis.

El actual neocaciquismo ha promovido, más que la producción, la adquisición de riqueza a través de operaciones y megaproyectos especulativos sin interés social, ni viabilidad económica. La dimensión que alcanzaron estos procesos hizo que el beneficio empresarial y el crecimiento económico no redundaran en mejoras de la calidad de vida del conjunto de la población, que tiene que pagar ahora los platos rotos del aquelarre de plusvalías, comisiones y obras sin sentido, de las que se beneficiaron algunos.

Más preocupante que los daños ecológicos y los endeudamientos económicos que han dejado las prácticas especulativas, resulta la herencia de stress psicológico, de crispación social y de bancarrota moral. 


\section{PERSPECTIVAS Y ALTERNATIVAS}

Hay que asumir que estamos sufriendo las consecuencias de un modelo inmobiliario agotado, que no resuelve los problemas que tiene planteados el país en estos momentos, lo que pide a gritos su reconversión.

Hay que diagnosticar el panorama "post burbuja" subrayando que se ha desplazado el problema desde la supuesta escasez originaria de suelo urbanizable, infraestructuras y viviendas, hacia un desmesurado exceso de los mismos... unido al enorme endeudamiento antes mencionado.

Los principales objetivos que se desprenden de ese diagnóstico son, reconvertir, sanear y/o hacer habitables, los excesivos stocks de suelo, infraestructuras y viviendas y paliar la carga del excesivo endeudamiento.

La definición de los problemas y objetivos señala la configuración del marco institucional y la elección de políticas e instrumentos. Las instituciones, políticas e instrumentos alternativos propuestos tendrían que ser, en la mayoría de los casos, justo los contrarios de los que han venido operando hasta el momento. Pues justo habría que situarlos en las antípodas de los actuales para orientar el metabolismo económico hacia la habitabilidad y el uso eficiente del patrimonio inmobiliario pasando de la vivienda como inversión, hacia la vivienda como bien de uso; desde la realización de plusvalías hacia el cobro de rentas; desde la vivienda libre hacia la vivienda social; desde la construcción nueva hacia el saneamiento, la reutilización, rehabilitación, y ocupación del suelo y el patrimonio inmobiliario construido...

Cambiar el modelo inmobiliario actual no exige descubrir la pólvora, ni hacer la revolución, sino mirar más allá de los Pirineos y fijarnos en otros países de capitalismo maduro (como Alemania o Suiza, en los que predomina el alquiler como régimen de tenencia mayoritario del stock de viviendas) que gestionan de forma más razonable su patrimonio inmobiliario... o seguir las orientaciones que marcan documentos que van desde el Libro verde del medio ambiente urbano, publicado por la UE en 1995... hasta Libro blanco de la sostenibilidad en el planeamiento urbano, publicado por el antiguo Ministerio de Vivienda en 2010 y el Libro verde de la sostenibilidad urbana y local, Ministerio de Agricultura, Alimentación y Medio Ambiente, 2012.

Las exigencias contempladas en estos documentos de una "nueva visión integrada" y un de "cambio de lógica" respecto a los enfoques parcelarios y pecuniarios habituales, se resumirían en la consideración de la ciudad como proyecto, con todas sus piezas. Y las exigencias habituales de "compromiso público institucional" tendrían que concretarse apoyando el proyecto urbano-territorial sobre la interacción de estas tres patas: un núcleo administrativo responsable capaz de gestionar con esa visión integrada, un sistema de información capaz describir el comportamiento y la evolución del sistema urbano-territorial (con especial referencias a los dos stocks fundamentales a gestionar en régimen de escasez: el territorio y el patrimonio construido); y un proceso que incentive y facilite la participación informada de los ciudadanos en la toma de decisiones.

El objetivo de paliar a la vez las necesidades de vivienda insatisfechas y el excesivo endeudamiento y falta de liquidez de hogares y empresas bancarias e inmobiliarias, pasa por gestionar más eficientemente el infrautilizado stock 
inmobiliario. Para ello hay que disponer de buena información sobre el stock inmobiliario en suelo e inmuebles y sobre las minusvalías, reconociendo el panorama y no ocultándolo. Además, la reconversión propuesta exige la entrada de nuevos actores en el monocorde panorama inmobiliario, gobernado por la vivienda libre y en propiedad. Debería facilitarse a la vez la desinversión inmobiliaria de las empresas bancarias e inmobiliarias y los hogares más endeudados, con la entrada de nuevas entidades mayoristas especializadas en gestionar viviendas en alquiler, libre y social, capaces de financiar sus inversiones recurriendo a los mercados financieros, como ocurre en los países antes mencionados. Esta doble diversificación inmobiliaria y financiera, permitiría paliar el absurdo panorama actual que enfrenta "casas sin gente a gente sin casa".

A la vista de lo anterior, la reconversión propuesta pasa obligadamente por reforzar la democracia participativa en el escalón local, para paliar el caciquismo que ha venido hundiendo el país. Hace falta un verdadero rearme democrático, unido a un rearme moral, para que la ciudadanía perciba a los especuladores como una vergonzosa plaga social y no como personas a imitar.

\section{REFERENCIAS BIBLIOGRÁFICAS:}

NAREDO y MONTIEL (2011) El modelo inmobiliario español y su culminación en el caso valenciano, Barcelona: Icaria.

NAREDO, J.M. (2015a) Raíces económicas del deterioro ecológico y social. Más allá de los dogmas, Madrid: Siglo XXI

NAREDO, J.M. (2015b). Economía, poder y política. Crisis y cambio de paradigma, Madrid: Díaz\&Pons . 